\title{
Updates and Critical Insights on Glissonian Approach in Liver Surgery
}

\author{
Demetrios Moris $^{1} \cdot$ Amir A. Rahnemai-Azar ${ }^{2} \cdot$ Diamantis I. Tsilimigras ${ }^{3}$ • \\ Ioannis Ntanasis-Stathopoulos ${ }^{3}$ - Hugo P. Marques $^{4}$ - Eleftherios Spartalis ${ }^{5}$. \\ Evangelos Felekouras $^{3}$ - Timothy M. Pawlik ${ }^{1}$
}

Received: 16 August 2017 / Accepted: 17 October 2017 / Published online: 3 November 2017

(C) 2017 The Society for Surgery of the Alimentary Tract

\begin{abstract}
Recent advances in surgical techniques have broadened the indications of surgical management of liver malignancies. Intraoperative bleeding is one of the known predictors of postoperative outcomes following liver surgery, signifying the importance of vascular control during liver resection. Furthermore, preservation of future liver remnant plays a critical role in prevention of post-hepatectomy liver failure as one of the main causes of postoperative morbidity and mortality. Glissonian approach liver resection offers an effective method for vascular inflow control while protecting future liver remnant from ischemiareperfusion injury. Several studies have demonstrated the feasibility of Glisson's pedicle resection technique in modern liver surgery with an acceptable safety profile. Moreover, with increasing popularity of minimally invasive surgery, laparoscopic liver resection via Glissonian approach has been shown to be superior to standard laparoscopic hepatectomy. Herein, we systematically review the role of Glissonian approach hepatectomy in current practice of liver surgery, highlighting its advantages and disadvantaged over other methods of vascular control.
\end{abstract}

Keywords Glissonian approach · Glisson's pedicle · Hepatectomy $\cdot$ Liver cancer $\cdot$ Liver resection $\cdot$ Liver malignancy

\section{Introduction}

Hepatic resection remains the cornerstone of treatment for liver malignancies. ${ }^{1,2}$ With recent advances in surgical

Timothy M. Pawlik

tim.pawlik@osumc.edu

1 Department of Surgery, Division of Surgical Oncology, The Ohio State University Wexner Medical Center, 395 W. 12th Ave., Suite 670, Columbus, OH, USA

2 Department of Surgery, Division of Surgical Oncology, University of Wisconsin Hospital, Madison, WI, USA

3 1st Department of Surgery, Laikon General Hospital, National and Kapodistrian University of Athens, Athens, Greece

4 Department of Surgery, Curry Cabral Hospital, Lisbon, Portugal

5 Laboratory of Experimental Surgery and Surgical Research, University of Athens Medical School, Athens, Greece technique, the indications for surgical treatment of hepatic malignancies has expanded with more strategies to resect tumors that traditionally have been considered unresectable. ${ }^{3-5}$ Intraoperative bleeding is a known predictor of postoperative morbidity and mortality following liver surgery, especially in cirrhotic patients. ${ }^{6,7}$ Several vascular clamping techniques ranging from full hilar to more selective segmental pedicle clamping have been described to prevent or control intraoperative hemorrhage. ${ }^{8}$ In general, the liver parenchyma is more tolerant to intermittent versus continuous pedicle clamping. In addition, extensive ischemia-reperfusion injury caused by hilar pedicle clamping may impair future liver remnant (FLR) function. ${ }^{9}$ The extrahepatic control of Glisson's pedicle, known as the Glissonian approach, was first introduced by LortatJacob et al. in 1952 as an alternative method to full hilar vascular clamping. ${ }^{10}$ The transhepatic approach was described by others later in $1965 .{ }^{11}$ Recently, the Glissonian approach has been increasingly proposed as a safe and efficient method for both open and laparoscopic liver surgery. ${ }^{12-16}$ The objective of the current study was to review systematically the data on the Glissonian approach in the practice of liver surgery. Specifically, we sought to highlight the potential advantages and disadvantages of the Glissonian approach. 


\section{Materials and Methods}

The review was conducted in accordance to the Preferred Reporting Items for Systematic Reviews and Meta-analysis (PRISMA) guidelines. ${ }^{17}$ Specifically, a systematic review of the English literature was performed utilizing MEDLINE/ PubMed and Web of Science databases with an end date of May 31, 2017 (Fig. 1). The MESH terms "Glissonian approach," "Glissonean approach," "liver surgery," "liver resection," "hepatectomy," "laparoscopic liver resection," and "laparoscopic hepatectomy" in combination with "liver cancer," "hepatic malignancy," and "liver malignancy" were searched in the title and/or abstract. The references of relevant articles were reviewed to identify additional eligible publications ("snow-balling" technique). Reference lists of the eligible studies, as well as meta-analyses and reviews pertinent to the topic, were manually assessed to identify any additional potentially eligible articles. Two authors (INS, DIT) independently performed extraction and cross-checking of the data. Any discrepancies were resolved by team consensus. Data were extracted (e.g., year of publication, size of patient population, type of vascular control, perioperative outcomes, morbidity, mortality) and then tabulated and cumulative analysis was performed when possible.

\section{Results and Discussion}

\section{Glissonian Versus Traditional Hilar Approach}

Structures in the hepatoduodenal ligament are dissected to expose the portal vein, hepatic artery, and bile duct when performing a standard "conventional" hepatectomy. ${ }^{18}$ After dissecting out these structures, an extrahepatic transection of the ipsilateral portal vein and hepatic artery can be performed to facilitate demarcation of the liver for the anticipated parenchymal transection. Depending on the location of the lesion, at other times, occlusion of the entire hepatoduodenal ligament (Pringle maneuver) may be preferred. Clamping of the portal triad at hepatic hilum (Pringle maneuver) controls vascular inflow and reduces blood loss during transection of the hepatic parenchyma. ${ }^{19}$ The Pringle maneuver may have limitations, however, as it has been associated with total liver ischemia, as well as possible adverse oncological outcomes. ${ }^{14,20}$

In an attempt to reduce blood loss, avoid hilar dissection, and decrease operative time, the Glissonian approach was proposed. ${ }^{12,21}$ According to ramification of the Glisson's pedicle tree, the liver is divided into three sections (left, middle, right) allowing highly selective control of these pedicles without the need for ultrasonographic or cholangiographic guidance (Fig. 2) ${ }^{18}$ Although ultrasound assistance is frequently not necessary, ultrasound can assist in the intraoperative identification of liver vascular structures. ${ }^{22-25}$ Moreover, ultrasound may help reduce blood loss during resection due to intraoperative identification of the vascular anatomy and the control of the segmental arteries and veins in liver surgery. In the extrahepatic Glissonian approach, the bifurcation of the pedicle tree is accessed through dissection of the hilar plate. Subsequently, the entire left or right pedicle is ligated and transected prior to hepatic resection (Figs. 3, 4, and 5). Compared with full hilar pedicle clamping (the Pringle maneuver), the Glissonian approach can help avoid ischemiareperfusion injury to the FLR, as well as mitigate any adverse general and cancer-specific outcomes. ${ }^{14}$

In particular, the Glissonian approach has gained popularity over the last decade due to its ease of approach and lack of technical complexity. ${ }^{18,21}$ Early reports that compared Glisson's pedicle transection with conventional hepatectomy demonstrated the feasibility and efficacy of the approach. For example, in a study of 90 patients who underwent major hepatectomy, Nakai et al. reported no difference in the amount of blood loss, operative duration, or postoperative complications comparing standard hilar dissection with the Glissonian approach. ${ }^{26}$ There was, however, a higher incidence of bile leak with the Glissonian approach, mainly in patients who underwent a left hemi-hepatectomy (conventional hepatectomy $7 \%$ vs. Glissonian approach $23.4 \% ; p=0.031$ ) (Table 1). ${ }^{26}$ Of note, bile leak following the Glissonian approach hepatectomy persisted in less than $5 \%$ of patients and typically was small and self-limiting. ${ }^{30}$ In a separate retrospective study, Giordano et al. study reported similar operative time, blood loss, postoperative morbidity, and mortality among patients who underwent extrahepatic Glissonian transection compared with hilar dissection. ${ }^{16}$

Mongolia et al. reported that the Glissonian pedicle approach had comparable surgical and long-term survival outcomes versus conventional liver resection. ${ }^{27}$ Similarly, in a prospective randomized trial, Figueras et al. compared hilar dissection versus the Glissonian approach among patients undergoing a major hepatectomy. ${ }^{15}$ Although en bloc transection of the Glisson's pedicle was faster than isolated ligation of each element in the hilar pedicle, the duration of pedicle clamping was shorter with hilar dissection, probably due to an initial period of Pringle maneuver applied for introduction of the stapler with the Glissonian approach. ${ }^{15}$ There were no differences between the two techniques in terms of perioperative and long-term outcomes. ${ }^{15}$ Ischemic injury to the FLR was, however, lower among patients who underwent a hepatectomy using the Glissonian approach, especially for patients with cirrhosis (Table 2). ${ }^{14}$ Therefore, minimizing the clamping time or the extent of ischemic zones with the Glissonian approach may provide an advantage especially among patients with underlying liver disease.

Other reports have noted a superiority of the Glissonian approach versus hilar dissection. For example, in a study by $\mathrm{Ji}$ et al. of patients with large $(>5 \mathrm{~cm})$ nodular $\mathrm{HCC}$, the 

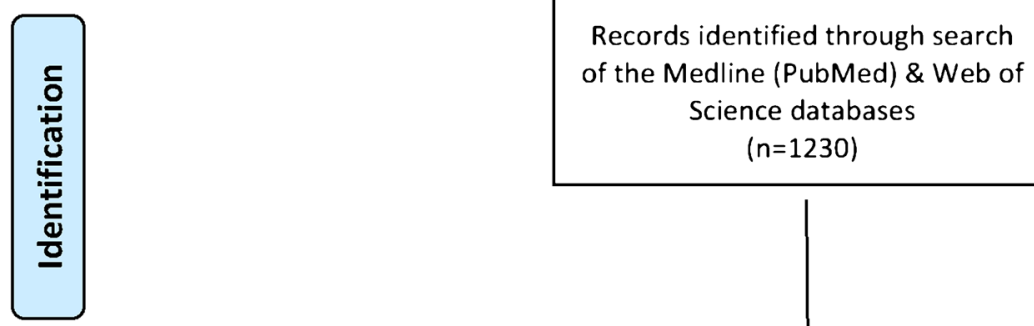

Records identified through search

of the Medline (PubMed) \& Web of Science databases

$(n=1230)$
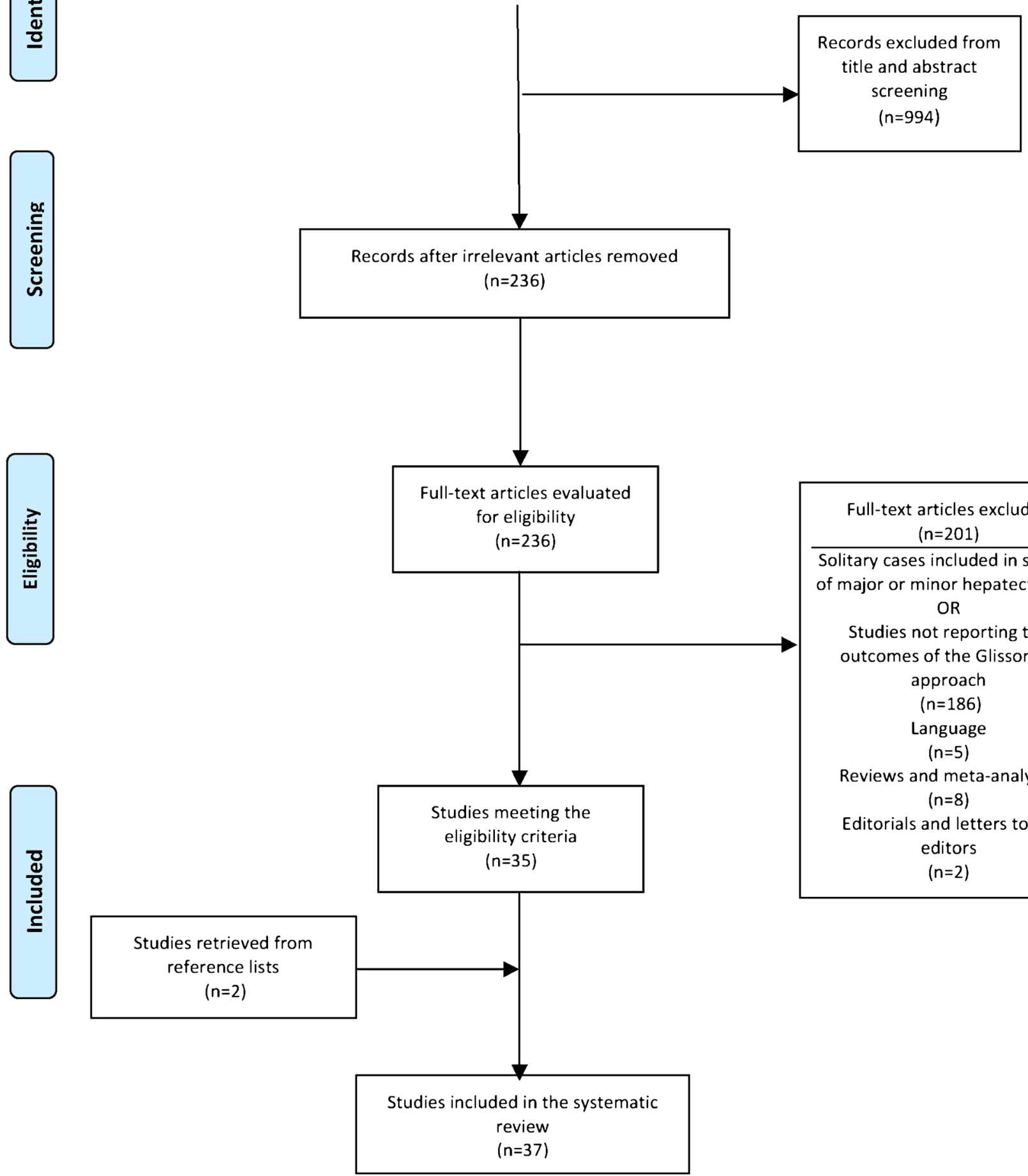

Full-text articles excluded ( $n=201)$

Solitary cases included in studies of major or minor hepatectomies OR

Studies not reporting the outcomes of the Glissonian approach ( $n=186)$ Language $(n=5)$

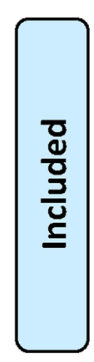

Reviews and meta-analyses $(n=8)$

Editorials and letters to the editors $(n=2)$

Fig. 1 Schematic diagram depicting how articles were selected for the systematic review

Glissonian approach was associated with shorter inflow interruption, lower amounts of blood loss and transfusion, and more rapid resolution of ascites (all $p<0.001) .^{31}$ Postoperative liver function tests, as well as 1- and 3-year survival, were comparable, however, among patients undergoing hepatic resection with the Glissonian versus traditional approach. $^{31}$ Other studies have suggested a possible survival benefit with the Glissonian approach. Specifically, Tsuruta 
Fig. 2 a The four anatomical landmarks and six gates in the caudal view. The schema shows the relationship between the six gates and Laennec's capsule. The gaps between Laennec's capsule and the Glissonean pedicle could be entered only at these six gates (red curved lines). Gate I: the caudal end of the Arantius' ligamentum, Gate II: the junction between the round ligament and the umbilical plate, Gate III: the right edge of the Glissonean pedicle root of the umbilical portion (Gup: G2 + 3+4), Gate IV: the left edge of the posterior extremity of the cystic plate or the anterior Glissonean pedicle, Gate $\mathrm{V}$ : the bifurcation of the right main Glissonean pedicle, Gate VI: the space between the posterior Glissonean pedicle and the G1c. b Intrahepatic Glissonian approach. This approach can provide access to secondary or even tertiary pedicles though small incisions at anatomic landmarks in the supra-hilar area (green curved lines). (Used with permission)
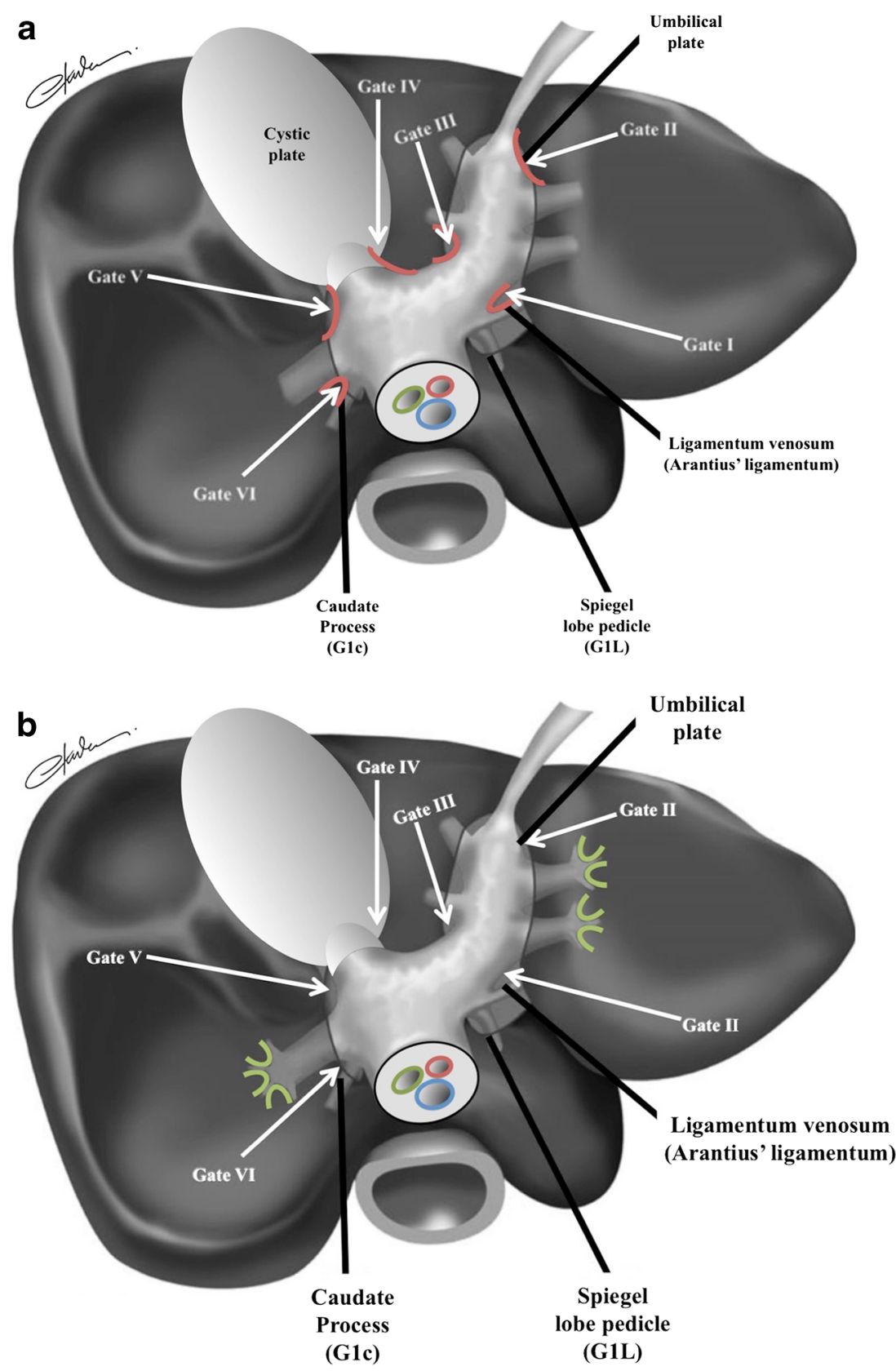

et al. reported that the Glissonian approach was associated with improved 5-year survival (Pringle maneuver $36.4 \%$ vs. Glissonian approach 64.7\%; $p<0.0001){ }^{32}$ Furthermore, the incidence of diffuse intrahepatic recurrence was lower among patients who underwent hepatectomy with the Glissonian approach $(p=0.0013)$. Some investigators have suggested that transection of the pedicles above the level of the bifurcation may prevent the intraoperative spread of neoplastic cells. ${ }^{32}$ To this end, Yamamoto et al. compared the effectiveness of "systematized hepatectomy" (Glissonian approach) with a partial hepatic resection among patients with small $(<5 \mathrm{~cm})$ nodular hepatocellular carcinoma. ${ }^{28}$ Although survival was similar among patients without extranodular tumor growth, patients with extranodular tumor invasion who underwent a Glissonian approach had a better higher 5-year survival (traditional $21 \%$ vs. Glissonian approach $67 \% ; p<0.001$ ) and a lower incidence of recurrence-related death (traditional $39.4 \%$ vs. Glissonian approach $11.4 \% ; p=0.011){ }^{28}$ These authors also postulated that the improved outcomes attributed to the Glissonian approach were related to the fact that HCC often invades central vascular structures and, therefore, ligation of a Glisson's pedicle may more effectively evade tumor spread. In a separate case-control study, the Glissonian approach was associated with a shorter operative duration, parenchymal 

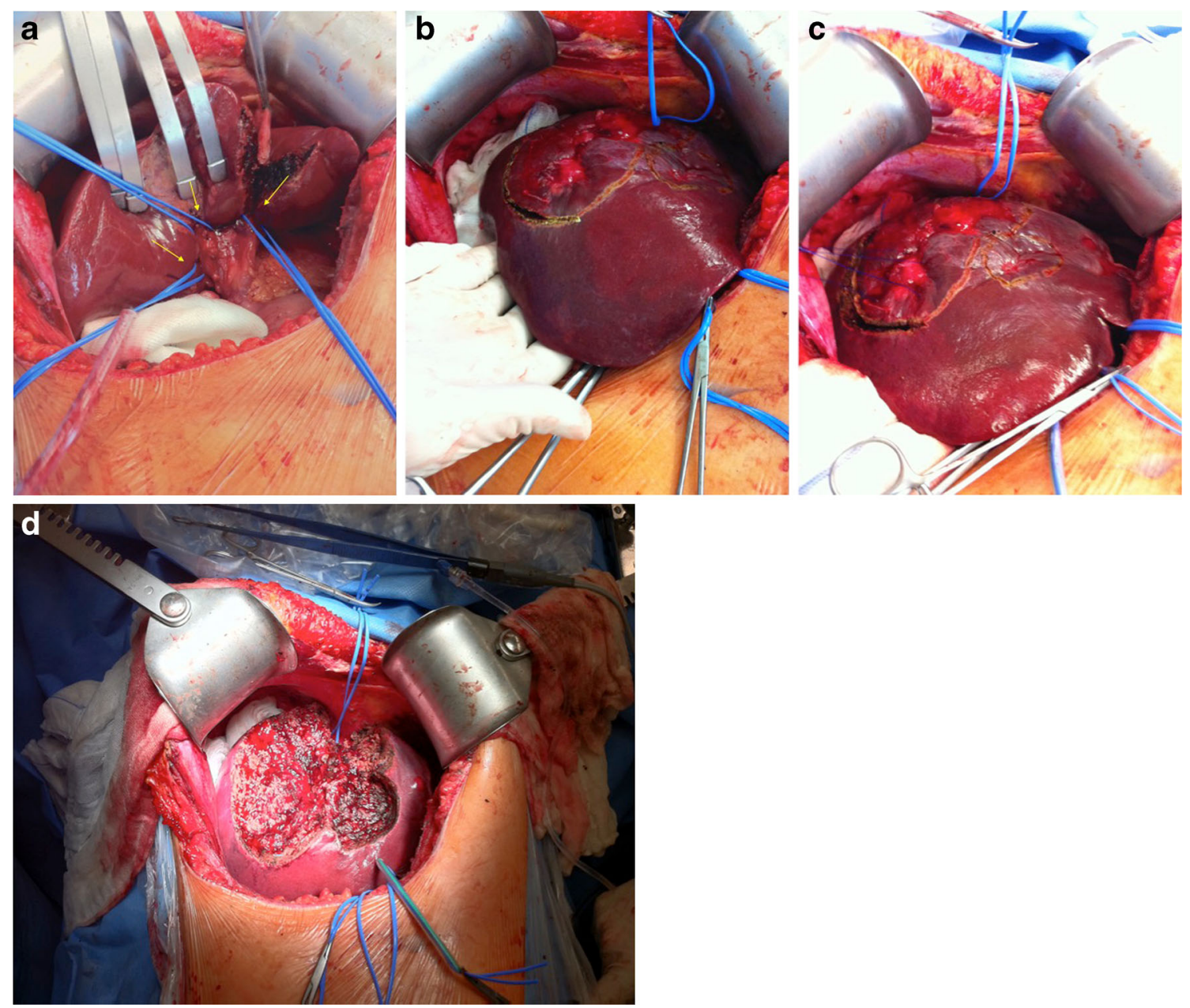

Fig. 3 Example of a patient undergoing several deep atypical parenchymal resections. a The right posterior pedicle (or right pedicle according to Takasaki), the right anterior pedicle (or median pedicle according to Takasaki), and the left pedicles were controlled separately.

transection time, ischemia time, as well as lower blood loss, and amount of blood transfusion compared with hilar

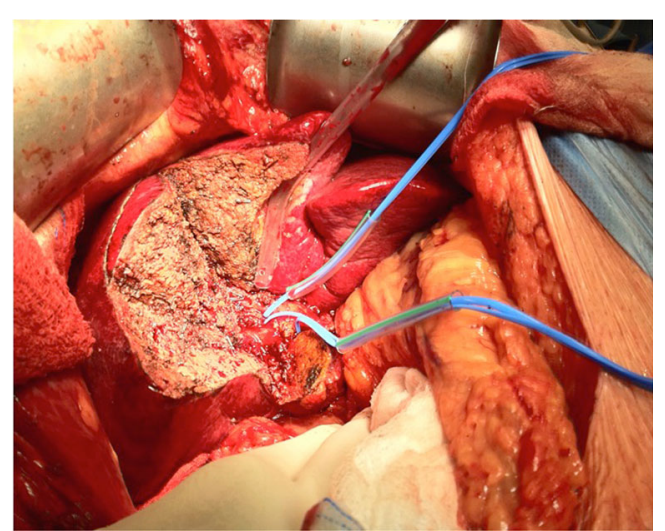

Fig. 4 A segmentectomy of segment 6 was performed for a hepatocellular carcinoma in a cirrhotic patient. The right anterior and posterior pedicles that had been previously controlled prior to resection can be seen (arrows)
Depending on the specific area of parenchymal resection, the right posterior (b) or right anterior (c) was clamped separately to avoid prolonged or repetitive pedicular clamping. d Demonstration of the liver following resection

dissection among patients undergoing major hepatectomy (all $p<0.05) .{ }^{29}$

\section{Intrahepatic Glissonian Approach}

Over the last decade, there has been an increasing emphasis on parenchymal-sparing liver surgery. ${ }^{33}$ Parenchymal-sparing hepatectomy typically involves removing the tumor/diseased portion of the liver while preserving as much of the normal, non-tumorous liver parenchyma as possible. The benefits of a parenchymal-sparing approach to liver surgery can be multifold including a decreased risk of post-hepatectomy liver insufficiency, as well as an increased opportunity for repeat hepatic resections if needed. ${ }^{34,35}$ To this end, an intrahepatic Glissonian approach facilitates a parenchymal-sparing approach to hepatic parenchymal transection. Specifically, an intrahepatic Glissonian approach provides access to secondary or even tertiary pedicles through small incisions at anatomic landmarks in the supra-hilar area (Fig. 3). ${ }^{36,37}$ An intrahepatic 

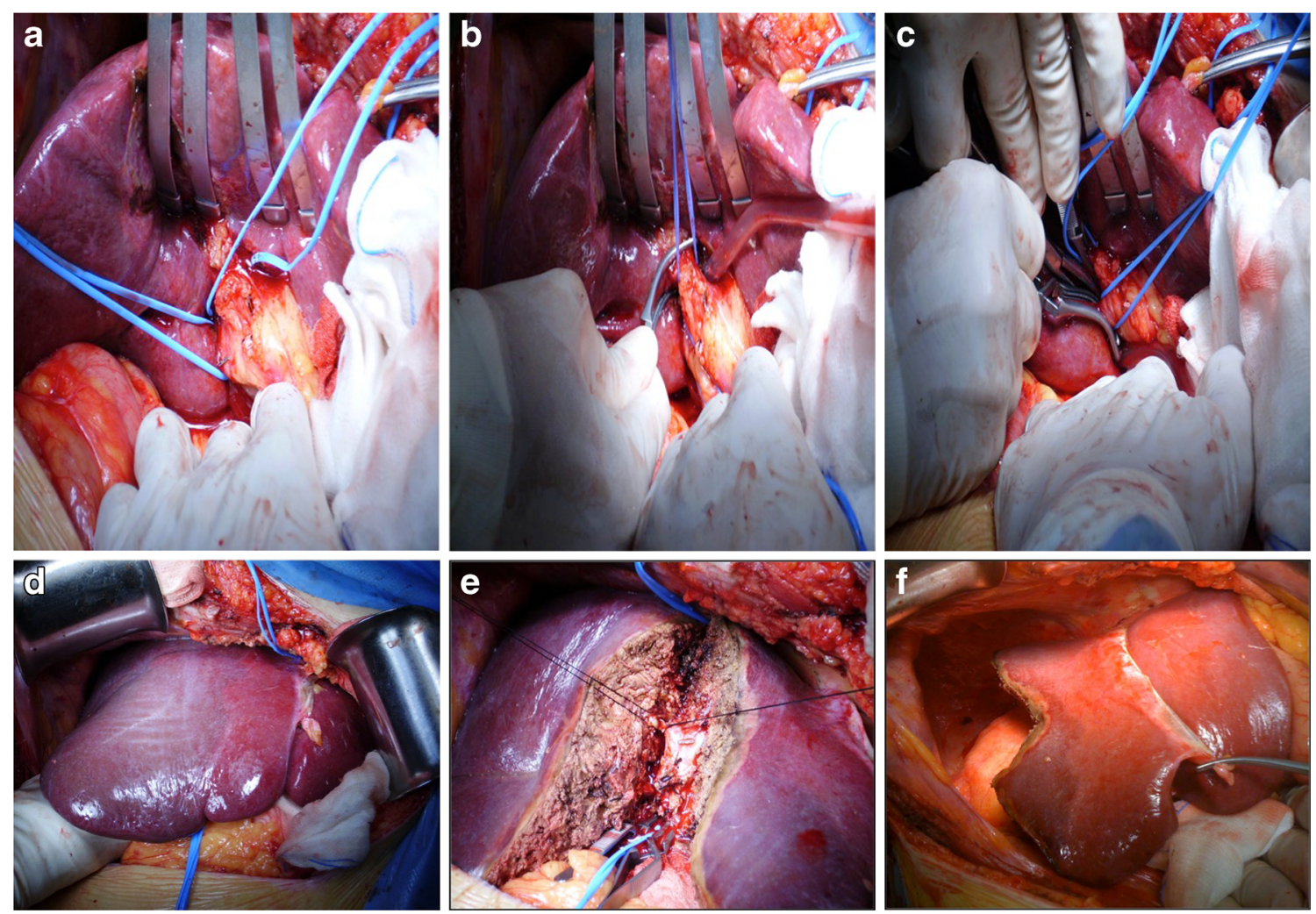

Fig. 5 An extended right posterior sectionectomy was performed in a patient with liver metastasis. After controlling the right anterior and right posterior pedicles (a) and subsequent clamping (b, c), right hemi- exclusion was performed (d). The parenchymal section line proceeded along the right anterior sector in a non-anatomic manner (e) allowing preservation of portions of segments $5 / 8$ (f)
Glissonian approach may be particularly helpful for tumors confined to a single segment of the liver. Accurate delineation and occlusion of the vasculature feeding the tumor-bearing anatomic zone facilitates more limited hepatectomies with preserving FLR. ${ }^{38}$ In fact, several studies have reported excellent outcomes using the Glissonian approach for singlesegment resections. ${ }^{38,39}$ In some instances, dissection of the hepatic pedicle bifurcation can be difficult, especially in the setting of repeat liver resection, which makes intrahepatic approach the preferred method over the extrahepatic method and classic hilar dissection in this clinical setting. ${ }^{36,37}$

In a study of 630 patients who underwent either a left hepatectomy or left lateral lobectomy, Chen et al. reported that the operative time was shorter $(77 \pm 35 \mathrm{~min})$ and intraoperative blood loss was lower $(110 \pm 250 \mathrm{~mL})$ using an intrahepatic Glissonian approach. ${ }^{36}$ In addition, there were no 30-day postoperative deaths. ${ }^{36}$ In a separate study of 182 patients who underwent either a right or left partial hepatectomy, Xia et al. similarly noted that intraoperative blood loss was much lower and there were no procedure-related morbidity or mortality associated with the Glissonian approach. ${ }^{37}$ The intrahepatic Glissonian approach has also been reported to be feasible for central hepatectomy (segments 4, 5, and 8), right anterior sectionectomy (segments 5 and 8), and right posterior sectionectomy (segments 6 and 7). ${ }^{40,41}$

\section{Glissonian Approach and Laparoscopic Liver Surgery}

There has been a growing adoption of minimally invasive surgical (MIS) approaches to liver resection. ${ }^{42,43}$ Of note, several reports have demonstrated the feasibility and safety of MIS right or left hepatectomy via Glissonian. ${ }^{44-53}$ The Glissonian approach can even be applied to other types of MIS hepatic resections including single-segment resection of S2, S5, and S6, as well as mesohepatectomy (segments 4, 5, and 8) with no procedure-related complications. ${ }^{45-47,54,55}$ Notably, Machado et al. has reported on almost every type of MIS liver resection using an intrahepatic Glissonian approach including left single segmentectomies (S1, S2, S3, S4), left bi-segmentectomies (S2-S3), right bisegmentectomies (S5-S8, S6-S7, S7-S8), left and right hemihepatectomies, right tri-sectionectomies, and mesohepatectomies. ${ }^{4-53}$ Machado and colleagues have also demonstrated the feasibility and safety of single-port MIS left lateral sectionectomy without any postoperative morbidity or mortality. ${ }^{56}$ In a 7-year observational study, MIS intrahepatic Glissonian approach was noted to have several advantages over standard MIS resection including shorter operative time, lower transfusion rates, fewer patients with a postoperative positive margin, as well as less morbidity and a shorter duration of hospital stay. ${ }^{44}$ 
Table 1 Studies comparing the Glissonian approach with the conventional liver resection (hilar dissection)

\begin{tabular}{|c|c|c|c|c|c|c|c|}
\hline \multirow[t]{2}{*}{ Study ID } & \multirow{2}{*}{$\begin{array}{l}\text { Years of } \\
\text { enrollment }\end{array}$} & \multirow[t]{2}{*}{ Study groups } & \multirow{2}{*}{$\begin{array}{l}\text { Patients, } \\
n\end{array}$} & \multirow[t]{2}{*}{ Outcomes } & \multicolumn{2}{|l|}{ Groups } & \multirow[t]{2}{*}{$p$ value } \\
\hline & & & & & $\begin{array}{l}\text { Hilar } \\
\text { dissection }\end{array}$ & $\begin{array}{l}\text { Glissonian } \\
\text { approach }\end{array}$ & \\
\hline \multirow[t]{5}{*}{ Nakai $(1999)^{26}$} & \multirow[t]{5}{*}{ 1988-1997 } & $\begin{array}{l}\text { Group 1: hilar } \\
\text { dissection }\end{array}$ & 43 & Operative time (min) & $284.1 \pm 79.7$ & $285.3 \pm 74.2$ & $p>0.05$ \\
\hline & & \multirow{4}{*}{$\begin{array}{l}\text { Group 2: Glissonian } \\
\text { approach }\end{array}$} & \multirow[t]{4}{*}{47} & Intraoperative bleeding $(\mathrm{mL})$ & $2100 \pm 1119.2$ & $2020.3 \pm 1215.5$ & $p>0.05$ \\
\hline & & & & Complications & $13(30.2 \%)$ & $20(42.6 \%)$ & $p>0.05$ \\
\hline & & & & Bile leakage & $3(7 \%)$ & $11(23.4 \%)$ & $p=0.031$ \\
\hline & & & & Hospital mortality & $3(6.9 \%)$ & $2(4.2 \%)$ & $p>0.05$ \\
\hline \multirow[t]{6}{*}{$\begin{array}{l}\text { Figueras } \\
\qquad(2003)^{15}\end{array}$} & \multirow[t]{6}{*}{$1998-2001$} & $\begin{array}{l}\text { Group 1: hilar } \\
\text { dissection }\end{array}$ & 40 & Operative time (min) & $247 \pm 54$ & $236 \pm 43$ & $p=0.4$ \\
\hline & & \multirow{5}{*}{$\begin{array}{l}\text { Group 2: Glissonian } \\
\text { approach }\end{array}$} & \multirow[t]{5}{*}{40} & Hilar dissection (min) & $70 \pm 26$ & $50 \pm 17$ & $p<0.001$ \\
\hline & & & & Pedicular clamping (min) & $43 \pm 15$ & $51 \pm 15$ & $p=0.015$ \\
\hline & & & & Intraoperative bleeding $(\mathrm{mL})$ & $887 \pm 510$ & $937 \pm 636$ & $p=0.7$ \\
\hline & & & & Morbidity rates & $23 \%$ & $33 \%$ & $p=0.3$ \\
\hline & & & & LOS (days) & 8 & 9 & $p=0.6$ \\
\hline \multirow[t]{9}{*}{$\begin{array}{l}\text { Chinburen } \\
\qquad(2015)^{27}\end{array}$} & \multirow[t]{9}{*}{ 2003-2012 } & $\begin{array}{l}\text { Group 1: hilar } \\
\text { dissection }\end{array}$ & 24 & Operative time (min) & $223.5 \pm 59.3$ & $269.16 \pm 93.9$ & $p=0.022$ \\
\hline & & \multirow{8}{*}{$\begin{array}{l}\text { Group 2: Glissonian } \\
\text { approach }\end{array}$} & \multirow[t]{8}{*}{45} & Intraoperative bleeding $(\mathrm{mL})$ & $522.2 \pm 528.7$ & $447.8 \pm 377.6$ & $p=0.953$ \\
\hline & & & & Complications & $13(54.2 \%)$ & $15(33.3 \%)$ & $p=0.093$ \\
\hline & & & & Postoperative mortality & $3(12.5 \%)$ & $4(8.9 \%)$ & $p=0.636$ \\
\hline & & & & LOS (days) & $21.3 \pm 9.6$ & $14.9 \pm 5.1$ & $p=0.004$ \\
\hline & & & & Overall survival (OS) & & & $p=0.664$ \\
\hline & & & & 1-year OS & $74 \%$ & $86 \%$ & $\begin{array}{l}\text { (refers to the } \\
\text { overall }\end{array}$ \\
\hline & & & & 3-year OS & $64 \%$ & $61 \%$ & $\begin{array}{l}\text { overall } \\
\text { cumulative }\end{array}$ \\
\hline & & & & 5-year OS & $55 \%$ & & $\begin{array}{l}\text { cumulative } \\
\text { survival) }\end{array}$ \\
\hline \multirow[t]{3}{*}{$\begin{array}{l}\text { Yamamoto } \\
\qquad(2001)^{28}\end{array}$} & \multirow[t]{3}{*}{ 1990-1994 } & $\begin{array}{l}\text { G1: partial hepatic } \\
\text { resection }\end{array}$ & 114 & $\begin{array}{l}\text { 5-year OS-single nodular } \\
\text { HCC without EG }\end{array}$ & $67 \%$ & $70 \%$ & $p=0.61$ \\
\hline & & $\begin{array}{l}\text { G2: Glissonian } \\
\text { approach }\end{array}$ & 90 & $\begin{array}{l}\text { 5-year OS-single nodular } \\
\text { HCC with EG }\end{array}$ & $21 \%$ & $67 \%$ & $p<0.001$ \\
\hline & & & & $\begin{array}{l}\text { Recurrence-related } \\
\text { mortality-single nodular } \\
\text { HCC with EG }\end{array}$ & $39.4 \%$ & $11.4 \%$ & $p=0.011$ \\
\hline \multirow{5}{*}{$\begin{array}{l}\text { Karamarkovic } \\
\qquad(2012)^{29}\end{array}$} & \multirow[t]{5}{*}{ 2009-2012 } & G1: hilar dissection & 34 & Operative time (min) & $246.62 \pm 56.55$ & $191.18 \pm 41.10$ & $p<0.001$ \\
\hline & & \multirow{4}{*}{$\begin{array}{l}\text { G2: Glissonian } \\
\text { approach }\end{array}$} & \multirow[t]{4}{*}{34} & Transection time (min) & $56.32 \pm 19.40$ & $38.94 \pm 14.56$ & $p<0.001$ \\
\hline & & & & Ischemic duration (min) & $41.18 \pm 12.80$ & $26.03 \pm 11.27$ & $p<0.001$ \\
\hline & & & & Intraoperative bleeding $(\mathrm{mL})$ & $344.71 \pm 166.25$ & $245.59 \pm 169.39$ & $p=0.018$ \\
\hline & & & & Blood transfusion $(\mathrm{mL})$ & $414.76 \pm 135.48$ & $322.86 \pm 102.07$ & $p=0.038$ \\
\hline
\end{tabular}

Statistically significant for $p<0.05$

$L O S$ length of stay, $E G$ extranodular growth, $H C C$ hepatocellular carcinoma, $O S$ overall survival

\section{Feasibility and Limitations}

While generally associated with low perioperative morbidity and mortality $(<1 \%)$, application of the Glissonian method can be technically challenging in certain cases. ${ }^{36,41,44}$ For example, Mouly et al. reported a feasibility rate of only $75 \%$ (24/ 32 ) for right hepatectomy, with incomplete clamping $(n=2)$ and clamping of the left portal pedicle due to aberrant portal vein anatomy $(n=6)$ as common reasons for technical failure. ${ }^{57}$ As such, when considering the Glissonian approach, the presence of portal vein anatomic variations should always be considered. Timely recognition of these alterations before or during the operation is of paramount importance. In addition, aberrant bile duct anatomy needs to be considered and detailed preoperative imaging should be performed to assess for this possibility; if biliary anatomy is unclear at the time of surgery, cholangiography should be considered to identify and help plan repair of any possible bile duct injury. ${ }^{44}$

When performing the Glissonian approach, gentle handling of anatomic structures is extremely important. While 
Table 2 Studies comparing the Glissonian approach with the Pringle maneuver

\begin{tabular}{|c|c|c|c|c|c|c|c|}
\hline \multirow[t]{2}{*}{ Study ID } & \multirow{2}{*}{$\begin{array}{l}\text { Years of } \\
\text { enrollment }\end{array}$} & \multirow[t]{2}{*}{ Study groups } & \multirow{2}{*}{$\begin{array}{l}\text { Patients, } \\
n\end{array}$} & \multirow[t]{2}{*}{ Outcomes } & \multicolumn{2}{|l|}{ Groups } & \multirow[t]{2}{*}{$p$ value } \\
\hline & & & & & $\begin{array}{l}\text { Pringle } \\
\text { maneuver }\end{array}$ & $\begin{array}{l}\text { Glissonian } \\
\text { approach }\end{array}$ & \\
\hline \multirow{7}{*}{$\begin{array}{l}\text { Figueras } \\
\qquad(2005)^{14}\end{array}$} & \multirow[t]{7}{*}{ 1999-2003 } & Group 1: Pringle maneuver & 39 & Operative time (min) & $207 \pm 48$ & $219 \pm 45$ & $p=0.24$ \\
\hline & & \multirow[t]{6}{*}{$\begin{array}{l}\text { Group 2: Glissonian } \\
\text { approach }\end{array}$} & \multirow[t]{6}{*}{41} & $\begin{array}{l}\text { Intraoperative bleeding } \\
(\mathrm{mL})\end{array}$ & $671 \pm 533$ & $735 \pm 397$ & $p=0.54$ \\
\hline & & & & Ischemic duration (min) & $41 \pm 14$ & $47 \pm 18$ & $p=0.07$ \\
\hline & & & & Transfusion, $n$ & $4(10 \%)$ & $6(15)$ & $p=0.54$ \\
\hline & & & & Complications & $15(38 \%)$ & $12(29 \%)$ & $p=0.38$ \\
\hline & & & & LOS (days) & $9.38 \pm 4.9$ & $8.15 \pm 3.8$ & $p=0.21$ \\
\hline & & & & In-hospital mortality & 0 & $1(2.4 \%)$ & $p=0.33$ \\
\hline \multirow[t]{4}{*}{$\mathrm{Ji}(2012)^{31}$} & \multirow[t]{4}{*}{ 2008-2011 } & Group 1: Pringle maneuver & 25 & Operative time (min) & $100.0 \pm 35.0$ & $80.0 \pm 25.0$ & $p=0.022$ \\
\hline & & \multirow{3}{*}{$\begin{array}{l}\text { Group 2: Glissonian } \\
\text { approach }\end{array}$} & \multirow[t]{3}{*}{25} & Inflow occlusion (min) & $45.0 \pm 13.0$ & $30.0 \pm 12.0$ & $p<0.001$ \\
\hline & & & & $\begin{array}{l}\text { Intraoperative bleeding } \\
(\mathrm{mL})\end{array}$ & $298.0 \pm 109.0$ & $145.0 \pm 20.0$ & $p<0.001$ \\
\hline & & & & LOS (days) & $14.0 \pm 2.1$ & $12.0 \pm 1.5$ & $p<0.001$ \\
\hline \multirow{2}{*}{$\begin{array}{l}\text { Tsuruta } \\
\qquad(2002)^{32}\end{array}$} & \multirow[t]{2}{*}{$\mathrm{N} / \mathrm{R}$} & Group 1: Pringle maneuver & 159 & 5-year survival & $36.4 \%$ & $64.7 \%$ & $p<0.0001$ \\
\hline & & $\begin{array}{l}\text { Group 2: Glissonian } \\
\text { approach }\end{array}$ & 100 & $\begin{array}{l}\text { Diffuse type intrahepatic } \\
\text { recurrence ( }>4 \text { lesions) }\end{array}$ & \multicolumn{2}{|c|}{$\begin{array}{l}\text { Significantly reduced in } \mathrm{G} 2 \\
\quad \text { compared to } \mathrm{G} 1(p=0.0013)\end{array}$} & \\
\hline
\end{tabular}

Statistically significant for $p<0.05$

$N / R$ not reported, LOS length of stay

encircling the Glisson's pedicles, forceful maneuvers to the surrounding parenchyma can sometimes result in excessive bleeding with resultant perioperative morbidity and mortality. In fact, difficulty in encircling the pedicles or parenchymal bleeding during liver dissection at the supra-hilar area are the two most common causes of technical failure. ${ }^{41}$ Such bleeding is more common in cirrhotic patients and patients with underlying portal hypertension. In addition, the inexperienced surgeon can induce parenchymal bleeding, as well as even injury to the pedicles. Finally, tumors located immediately adjacent to the hepatic hilum require special attention. Because ligation or transection of Glisson's pedicles that may harbor malignant cells can result in intraoperative tumor spread and recurrence, the Glissonian approach may not be the best approach for tumors immediately adjacent to the hilum.

It is also important to note that other limitations of the Glissonian approach may be under-reported. Specifically, the lack of data on potential negative consequences/outcomes associated with the Glissonian approach may be due to publication bias. In addition, given that most studies were retrospective in nature, selection bias may also have impacted the results. The majority of the studies also included heterogenous patient populations in terms of diagnosis, concomitant liver status (e.g., steatosis, cirrhosis), as well as technical modifications (e.g., combining Pringle maneuver or partial IVC interruption). The ongoing Classical Procedure Versus Intrahepatic Glisson's Approach (LAHIGA) trial is designed to compare the classical resection versus intrahepatic Glisson's approach for laparoscopic anatomical hepatectomy. The objective of this trial is to evaluate the feasibility, safety, and limitations of the Glissonian approach, as well as assess outcomes among patients with malignant and benign liver diseases (ClinicalTrials.gov Identifier: NCT01567631).

\section{Conclusion}

The Glissonian approach, either extrahepatic or intrahepatic has been demonstrated to be a safe and feasible method in liver surgery. In fact, the Glissonian approach may be preferred in many clinically settings as it is associated with shorter operative times, lower blood loss, and low morbidity. In addition, the Glissonian approach can be utilized for MIS resections and may be superior to standard MIS hepatectomy. While the Glissonian approach has many potential benefits, appropriate application of this technique requires accurate preoperative tumor localization, identification of potential anatomic pedicle variations, as well as expertise on the part of the surgeon to be successful.

\section{References}

1. Moris D, Vernadakis S, Papalampros A, Petrou A, Dimitroulis D, Spartalis E, et al. The effect of Guidelines in surgical decision making: The paradigm of hepatocellular carcinoma. Journal of BUON : official journal of the Balkan Union of Oncology. 2016;21(6):1332-6. 
2. Moris D, Dimitroulis D, Vernadakis S, Papalampros A, Spartalis E, Petrou A, et al. Parenchymal-sparing Hepatectomy as the New Doctrine in the Treatment of Liver-metastatic Colorectal Disease: Beyond Oncological Outcomes. Anticancer research. 2017;37(1): 9-14.

3. Moris D, Felekouras E. Ignore reality but not the consequences of its ignorance: Broaden guidelines in surgery of hepatocellular carcinoma. Hepatology. 2017;65(5):1772-3.

4. Petrou A, Neofytou K, Mihas C, Bagenal J, Kontos M, Griniatsos J, et al. Radiofrequency ablation-assisted liver resection: a step toward bloodless liver resection. Hepatobiliary \& Pancreatic Diseases International : HBPD INT. 2015;14(1):69-74.

5. Moris D, Ronnekleiv-Kelly S, Rahnemai-Azar AA, Felekouras E, Dillhoff M, Schmidt C, et al. Parenchymal-Sparing Versus Anatomic Liver Resection for Colorectal Liver Metastases: a Systematic Review. Journal of Gastrointestinal Surgery : official journal of the Society for Surgery of the Alimentary Tract. 2017.

6. Bennett S, Baker LK, Martel G, Shorr R, Pawlik TM, Tinmouth A, et al. The impact of perioperative red blood cell transfusions in patients undergoing liver resection: a systematic review. HPB : the official journal of the International Hepato Pancreato Biliary Association. 2017;19(4):321-30.

7. Margonis GA, Kim Y, Samaha M, Buettner S, Sasaki K, Gani F, et al. Blood loss and outcomes after resection of colorectal liver metastases. The Journal of Surgical Research. 2016;202(2):473-80.

8. Spolverato G, Pawlik TM. Liver-directed therapies: surgical approaches, alone and in combination with other interventions. American Society of Clinical Oncology educational book American Society of Clinical Oncology Meeting. 2014:101-10.

9. Dimitroulis D, Moris D, Pikoulis E, Spartalis E, Kontadakis G, Vrugt B, et al. Variable Pringle Maneuvers and Effect on Intestinal Epithelium in Rats. A Pilot Experimental Study in Rats. PloS one. 2015;10(10):e0140707.

10. Lortat-Jacob JL, Robert HG, Henry C. [Case of right segmental hepatectomy]. Memoires Academie de chirurgie. 1952;78(8-9): 244-51.

11. Ton That T, Nguyen Duong Q. [Segmentary hepatectomy by transparenchymatous vascular ligation]. La Presse medicale. 1965;73(52):3015-7.

12. Launois B, Sutherland FR, Harissis H. A new technique of HeppCouinaud hepaticojejunostomy using the posterior approach to the hepatic hilum. Journal of the American College of Surgeons. 1999;188(1):59-62.

13. Machado MA, Herman P, Machado MC. A standardized technique for right segmental liver resections. Archives of Surgery. 2003;138(8):918-20.

14. Figueras J, Llado L, Ruiz D, Ramos E, Busquets J, Rafecas A, et al. Complete versus selective portal triad clamping for minor liver resections: a prospective randomized trial. Annals of Surgery. 2005;241(4):582-90.

15. Figueras J, Lopez-Ben S, Llado L, Rafecas A, Torras J, Ramos E, et al. Hilar dissection versus the "glissonean" approach and stapling of the pedicle for major hepatectomies: a prospective, randomized trial. Annals of Surgery. 2003;238(1):111-9.

16. Giordano M, Lopez-Ben S, Codina-Barreras A, Pardina B, Falgueras L, Torres-Bahi S, et al. Extra-Glissonian approach in liver resection. HPB : the official journal of the International Hepato Pancreato Biliary Association. 2010;12(2):94-100.

17. Moher D, Liberati A, Tetzlaff J, Altman DG, Group P. Preferred reporting items for systematic reviews and meta-analyses: the PRISMA statement. Journal of Clinical Epidemiology. 2009;62(10):1006-12.

18. Takasaki K. Glissonean pedicle transection method for hepatic resection: a new concept of liver segmentation. Journal of Hepatobiliary-pancreatic Surgery. 1998;5(3):286-91.
19. Man K, Fan ST, Ng IO, Lo CM, Liu CL, Wong J. Prospective evaluation of Pringle maneuver in hepatectomy for liver tumors by a randomized study. Annals of Surgery. 1997;226(6):704-11; discussion 11-3.

20. Gurusamy KS, Kumar Y, Sharma D, Davidson BR. Methods of vascular occlusion for elective liver resections. The Cochrane Database of Systematic Reviews. 2007(4):CD006409.

21. Takasaki K, Kobayashi S, Tanaka S, Saito A, Yamamoto M, Hanyu F. Highly anatomically systematized hepatic resection with Glissonean sheath code transection at the hepatic hilus. International Surgery. 1990;75(2):73-7.

22. Patel NA, Roh MS. Utility of intraoperative liver ultrasound. The Surgical Clinics of North America. 2004;84(2):513-24.

23. Bismuth $\mathrm{H}$, Castaing D, Garden OJ. The use of operative ultrasound in surgery of primary liver tumors. World Journal of Surgery. 1987;11(5):610-4.

24. Jrearz R, Hart R, Jayaraman S. Intraoperative ultrasonography and surgical strategy in hepatic resection: What difference does it make? Canadian Journal of Surgery Journal canadien de chirurgie. 2015;58(5):318-22.

25. Donadon M, Costa G, Torzilli G. State of the art of intraoperative ultrasound in liver surgery: current use for staging and resection guidance. Ultraschall in der Medizin. 2014;35(6):500-11; quiz 12-3.

26. Nakai T, Koh K, Funai S, Kawabe T, Okuno K, Yasutomi M. Comparison of controlled and Glisson's pedicle transections of hepatic hilum occlusion for hepatic resection. Journal of the American College of Surgeons. 1999;189(3):300-4.

27. Chinburen J, Gillet M, Yamamoto M, Enkh-Amgalan T, Taivanbaatar E, Enkhbold C, et al. Impact of Glissonean pedicle approach for centrally located hepatocellular carcinoma in mongolia. International Surgery. 2015;100(2):268-74.

28. Yamamoto M, Takasaki K, Ohtsubo T, Katsuragawa H, Fukuda C, Katagiri S. Effectiveness of systematized hepatectomy with Glisson's pedicle transection at the hepatic hilus for small nodular hepatocellular carcinoma: retrospective analysis. Surgery. 2001;130(3):443-8.

29. Karamarkovic A, Doklestic K, Milic N, Djukic V, Bumbasirevic V, Sijacki A, et al. Glissonean pedicle approach in major liver resections. Hepato-gastroenterology. 2012;59(118):1896-901.

30. Capussotti L, Borgonovo G, Bouzari H, Smadja C, Grange D, Franco D. Results of major hepatectomy for large primary liver cancer in patients with cirrhosis. The British Journal of Surgery. 1994;81(3):427-31.

31. Ji B, Wang Y, Wang G, Liu Y. Curative resection of hepatocellular carcinoma using modified Glissonean pedicle transection versus the Pringle maneuver: a case control study. International Journal of Medical Sciences. 2012;9(10):843-52.

32. Tsuruta K, Okamoto A, Toi M, Saji H, Takahashi T. Impact of selective Glisson transection on survival of hepatocellular carcinoma. Hepato-gastroenterology. 2002;49(48):1607-10.

33. Moris D, Ronnekleiv-Kelly S, Rahnemai-Azar AA, Felekouras E, Dillhoff M, Schmidt C, et al. Parenchymal-Sparing Versus Anatomic Liver Resection for Colorectal Liver Metastases: a Systematic Review. Journal of Gastrointestinal Surgery : official journal of the Society for Surgery of the Alimentary Tract. 2017;21(6): 1076-85.

34. Spolverato G, Bagante F, Aldrighetti L, Poultsides GA, Bauer TW, Fields RC, et al. Management and outcomes of patients with recurrent neuroendocrine liver metastasis after curative surgery: An international multi-institutional analysis. Journal of Surgical Oncology. 2017;116(3):298-306.

35. Lafaro K, Buettner S, Maqsood H, Wagner D, Bagante F, Spolverato G, et al. Defining Post Hepatectomy Liver Insufficiency: Where do We stand? Journal of Gastrointestinal 
Surgery : official journal of the Society for Surgery of the Alimentary Tract. 2015;19(11):2079-92.

36. Chen XP, Qiu FZ. A simple technique ligating the corresponding inflow and outflow vessels during anatomical left hepatectomy. Langenbeck's Archives of Surgery. 2008;393(2):227-30; discussion 31-4.

37. Xia F, Li G, Lau WY, Ma KS, Bie P. Intrahepatic Glissonian approach and outflow vascular occlusion during partial hepatectomy. Hepatobiliary \& Pancreatic Diseases International : HBPD INT. 2014;13(1):101-4.

38. Doklestic K, Djukic V, Bumbasirevic V, Jovanovic B, Karamarkovic A. Segment-oriented liver resections based on posterior intrahepatic glissonian approach. Acta chirurgica Iugoslavica. 2012;59(3):41-8.

39. Hu JX, Dai WD, Miao XY, Zhong DW, Huang SF, Wen Y, et al. Anatomic resection of segment VIII of liver for hepatocellular carcinoma in cirrhotic patients based on an intrahepatic Glissonian approach. Surgery. 2009;146(5):854-60.

40. Machado MA, Herman P, Machado MC. Intrahepatic Glissonian approach for pedicle control during anatomic mesohepatectomy. Surgery. 2007;141(4):533-7.

41. Figueroa R, Laurenzi A, Laurent A, Cherqui D. Perihilar Glissonian Approach For Anatomical Parenchymal Sparing Liver Resections: Technical Aspects: The Taping Game. Annals of Surgery. 2016.

42. Okunrintemi V, Gani F, Pawlik TM. National Trends in Postoperative Outcomes and Cost Comparing Minimally Invasive Versus Open Liver and Pancreatic Surgery. Journal of Gastrointestinal Surgery : official journal of the Society for Surgery of the Alimentary Tract. 2016;20(11):1836-43.

43. Bagante F, Spolverato G, Strasberg SM, Gani F, Thompson V, Hall BL, et al. Minimally Invasive vs. Open Hepatectomy: a Comparative Analysis of the National Surgical Quality Improvement Program Database. Journal of Gastrointestinal Surgery : official journal of the Society for Surgery of the Alimentary Tract. 2016;20(9):1608-17.

44. Machado MA, Surjan RC, Basseres T, Schadde E, Costa FP, Makdissi FF. The laparoscopic Glissonian approach is safe and efficient when compared with standard laparoscopic liver resection: Results of an observational study over 7 years. Surgery. 2016;160(3):643-51.

45. Ho KM, Han HS, Yoon YS, Cho JY, Choi YR, Jang JS, et al. Laparoscopic Anatomical Segment 2 Segmentectomy by the Glissonian Approach. Journal of Laparoendoscopic \& Advanced Surgical Techniques Part A. 2016.
46. Ahn KS, Han HS, Yoon YS, Cho JY, Kim JH. Laparoscopic anatomical S5 segmentectomy by the Glissonian approach. Journal of Laparoendoscopic \& Advanced Surgical Techniques Part A. 2011;21(4):345-8.

47. Mizuno T, Sheth R, Yamamoto M, Kang HS, Yamashita S, Aloia TA, et al. Laparoscopic Glissonean Pedicle Transection (Takasaki) for Negative Fluorescent Counterstaining of Segment 6. Annals of Surgical Oncology. 2017;24(4):10467.

48. Machado MAC, Surjan R, Basseres T, Makdissi F. Laparoscopic Parenchymal-Sparing Liver Resections Using the Intrahepatic Glissonian Approach. Annals of Surgical Oncology. 2017.

49. Machado MA, Makdissi FF, Galvao FH, Machado MC. Intrahepatic Glissonian approach for laparoscopic right segmental liver resections. American Journal of Surgery. 2008;196(4):e38-42.

50. Machado MA, Makdissi FF, Herman P, Surjan RC. Intrahepatic Glissonian approach for pure laparoscopic left hemihepatectomy. Journal of Laparoendoscopic \& Advanced Surgical Techniques Part A. 2010;20(2):141-2.

51. Machado MA, Almeida FA, Makdissi FF, Surjan RC, Cunha-Filho GA. Video. One-stage laparoscopic bisegmentectomy 7-8 and bisegmentectomy 2-3 for bilateral colorectal liver metastases. Surgical Endoscopy. 2011;25(6):2011-4.

52. Machado MA, Kalil AN. Glissonian approach for laparoscopic mesohepatectomy. Surgical Endoscopy. 2011;25(6):2020-2.

53. Machado MA, Surjan RC, Makdissi FF. Video: intrahepatic Glissonian approach for pure laparoscopic right hemihepatectomy. Surgical Endoscopy. 2011;25(12):3930-3.

54. Jang JY, Han HS, Yoon YS, Cho JY, Choi Y, Lee W, et al. ThreeDimensional Laparoscopic Anatomical Segment 8 Liver Resection with Glissonian Approach. Annals of Surgical Oncology. 2017;24(6):1606-9.

55. Ho CM, Wakabayashi G, Nitta H, Takahashi M, Takahara T, Ito $\mathrm{N}$, et al. Total laparoscopic limited anatomical resection for centrally located hepatocellular carcinoma in cirrhotic liver. Surgical endoscopy. 2013;27(5):1820-5.

56. Machado MA, Surjan RC, Makdissi FF. Intrahepatic glissonian approach for single-port laparoscopic liver resection. Journal of Laparoendoscopic \& Advanced Surgical Techniques Part A. 2014;24(8):534-7.

57. Mouly C, Fuks D, Browet F, Mauvais F, Potier A, Yzet T, et al. Feasibility of the Glissonian approach during right hepatectomy. HPB : the official journal of the International Hepato Pancreato Biliary Association. 2013;15(8):638-45. 